\title{
Comments
}

\section{Don't Know Much About the Middle Ages: Posner on Law and Literature}

\author{
Stanley Fish $\uparrow$
}

The thesis of Richard Posner's Law and Literature: A Relation Reargued $^{x}$ is that the study of literature and the interpretation of statutes are very different activities and that one "has little to contribute"2 to the other. Let me say at the outset that Judge Posner is right. Literary and legal interpretation are distinct and the skills they separately require are not readily convertible. But while Posner's large point is well taken, the reasons with which he supports it are not, for they take the form of a series of distinctions no one of which can be maintained.

The basic distinction concerns the vexed matter of intention and is framed in terms made familiar to us by recent debates about constitutional interpretation. There are according to Posner two ways of reading, one that "requires [the interpreter] to discern" the intention of the author or authors of a text and another that requires the interpreter "merely to assign some coherent and satisfying meaning" to a text independently of what any author might or might not have intended. ${ }^{3}$ The first kind of reading is appropriate for legal texts, while the second, identified by Posner as "New Critical," is appropriate for literary texts." While it would be possible in Posner's view to read either kind of text in either way-to interpret a poem as the realization of a specific intention or to interpret a

\footnotetext{
† Arts and Sciences Professor of English and Professor of Law, Duke University.

1. Posner, Law and Literature: A Relation Reargued, 72 VA. L. Rev. 1351 (1986) [hereinafter cited by page number only].

2. P. 1351.

3. Pp. 1361-62.

4. P. 1362 .
} 
statute as if it were an "interesting verbal artifact" - the results would be "otiose" 6 and distorting, reducing the richness of a beautiful artifact to the statement of an author's "banal" intention" on the one hand, depriving the words of a statute "of their historical context," constrain, on the other. It is clear that for Posner, as for many others, the issue of intention is one with the issue of constraint. Those who ignore intention, either because they are bad jurists or good literary critics, cut themselves loose from contextual constraints; while those who defer to intention allow contextual constraints to limit the scope of their interpretive activity.

Every part of this picture is wrong. There is only one way to read or interpret and that is the way of intention; but to read intentionally is not to be constrained relative to some other (non-existent) way of reading. The reason for both truths is the same: Words are intelligible only within the assumption of some context of intentional production, some already in-place pre-decision as to what kind of person, with what kind of purposes in relation to what specific goals in a particular situation, is speaking or writing. To approach the matter from the other direction: Meanings are not embedded in words but emerge and are perspicuous in the light of background conditions of intelligibility. One could not "merely ... assign some coherent . . . meaning"9 to a text independent of a consideration of intention because any meaning one might assign would be thinkable only in the light of an intentional structure already assumed in advance. In those cases in which meanings seem immediately available without recourse to anything but the words themselves, it is because the intentional structure-the conditions of intelligibility that limit the meanings words can have before they are produced-is so deeply in place that we are not aware of it and seem to experience its effects directly, without mediation. Consider the small example of the utterance "Can you pass the salt?," immediately construed by the vast majority of native speakers as a request for performance of a specific action rather than as a question about the hearer's physical abilities; but this is so only because in the very hearing of the utterance we assume the meal-time setting populated by agents concerned with eating and drinking in the context of communal resources. If one varies the setting and reconceives it as a conversation between a doctor and a patient recovering from surgery, the utterance "Can you pass the salt?" could indeed be heard as a question about the hearer's physical ability, and could be so heard immediately and literally. I say "literally" to anticipate and prevent the mistake of thinking that

$\begin{array}{ll}\text { 5. } & \text { P. } 1363 . \\ \text { 6. } & \text { P. } 1364 . \\ \text { 7. } & \text { P. } 1367 . \\ \text { 8. } & \text { P. } 1364 . \\ \text { 9. } & \text { P. } 1362 .\end{array}$ 
what the example displays is a distinction between the literal meaning of an utterance and the meaning it acquires when placed in a particular context. Both meanings-the meaning of "request for performance" and the meaning of "inquiry into one's capacities"-are literal given the inplace force of some intentional context of production. Independently of some such already assumed context (and of course there could be many more than two) the utterance wouldn't have any meaning at all, and indeed wouldn't be an utterance, but merely a succession of noises or marks.

To put the point proverbially, intentions (or their assumption) come first, meanings second; and there can therefore be no distinction between intentional construing and some other, more free-wheeling kind. But this does not mean that interpretation is as safely constrained as some proponents of intentionalism claim it is, because while it is true that interpretation cannot proceed independent of intention, it is also true that intentions are themselves interpretively produced and therefore cannot serve (except in the most general and non-voluntarist sense) as a check on interpretive activity. In the example of "Gan you pass the salt?" it is always possible that someone at a dinner table may hear the question as one about his abilities, or that a patient may hear his doctor asking him to pass the salt (perhaps as a preliminary to an experiment). The fact that interpretation is irremediably intentional means only that one cannot choose between intentional reading and something else; but that still leaves the problem of determining exactly what the intention of which an utterance is the expression is. Since one cannot read back from the utterance to the intention (for that would be possible only if utterances were meaningful apart from intention, or had as part of their meaning a specification of the intention behind them), the intention must be supplied or constructed by the very interpreter who will then cite it in support of the meanings he "finds."

This conclusion may seem paradoxical, but it is not: All interpretation is intentional-assuming as the ground of its possibility a purposeful agent who has produced its object-but intentions do not constrain interpretation because the shape of the agent's purpose can itself be the matter of interpretive dispute. Undoing the distinction between reading with and without the anchor of intention also undoes the possibility of distinguishing between reading that is constrained and reading that is not, and this in turn undoes every distinction invoked by Posner in the course of his essay. I have myself counted fifteen, and they are all the same: Each posits an opposition between an interpretive activity that is answerable to public (factual, historical) and formal (verbal, logical) requirements, and an interpretive activity that is (at least relatively) free to go its own untrammeled way. In addition to the one already noted (between intentional and non-intentional interpretation) there are (1) the distinction between "in- 
terpretation" and "construction"; 10 (2) the distinction between words moored by history and context and words "wrenched free of their historical context";11 (3) the distinction between defined and "undefined lawmaking power",12 (4) the implied distinction between "highly specific language" and vague, non-specific language; ${ }^{13}$ (5) the distinction between legislation that limits the judiciary and legislation that gives the judiciary a "blank check"; ${ }^{14}$ (6) the distinction between language (poetry, for example) that is simply "beautiful and moving" and language that has legal or political "significance"; 15 (7) the distinction between verbal production that is purposeful and occasional and verbal production that is "unconscious" or the effusion of genius; (8) the distinction between language bounded by "period and culture" and language that is able to "transcend boundaries" because it has a "certain generality and even universality," i.e. means nothing in particular:16 (9) the distinction between bound and free ("irresponsible") reading; ${ }^{17}(10)$ the distinction between judging as an activity constrained by "authoritative texts" and literary criticism as an activity that deals with texts that are themselves detached from issues of authority and power; ${ }^{18}$ (11) the distinction between non-ambiguous and ambiguous texts; ${ }^{19}(12)$ the distinction between non-rhetorical and rhetorical modes of discourse; (13) the distinction between scientific discourse and discourse less responsible to canons of logic and proof ${ }^{20}(14)$ the distinction between neutral, colorless language and language colored by style, ${ }^{21}(15)$ the distinction between scientific language and persuasive language. ${ }^{22}$

Since everything that Posner says flows from these distinctions, they are, in the end, what he is asserting, and I contend that none of them can be maintained, at least not in the way required by his argument. Consider for example the cluster formed by numbers 12 through 15. Scientific language, according to Posner, is distinguished by logic rather than style; that is to say (and these claims are of course interchangeable), scientific discourse relies not on rhetoric, but on something akin to mathematical demonstration, ${ }^{23}$ and it is the nature of mathematical demonstration or experimental proof to dispense with the techniques of persuasion, techniques

\footnotetext{
10. P. 1360 .

11. Pp. 1364-65.

12. P. 1365.

13. Id.

14. P. 1366.

15. Id.

16. P. 1369.

17. P. 1370 .

18. Pp. 1370-71.

19. P. 1371.

20. P. 1376.

21. Id.

22. P. 1378 .

23. P. 1376.
} 
more appropriate to "areas of uncertainty" where "direct confirmation" of a hypothesis is unavailable. ${ }^{24}$ Within its circle this is a tight argument, but the argument falls with the fall of its basic premise: "Not all modes of discourse are rhetorical." ${ }^{\text {"25 }}$ All modes of discourse are rhetorical, where "rhetorical" means proceeding on the basis of assumptions and distinctions that are open to challenge, even though there may be times when no one is challenging them. The derivations that make up a scientific proof or a deductive argument in law rely for their force-that is, for their persuasiveness-on distinctions (such as that between rest and motion or public and private) that have themselves been put in place by debates just like those in relation to which they are now regarded as uncontroversial and directly confirming. It is because they are now (that is, for a time) uncontroversial that the assertion of such distinctions will be thought as devoid of "style"; but in fact it will be assertion in a style that by virtue of an institutional success has won the right to offer itself as impersonal, as proceeding from no particular point of view. The difference then between science or law, on the one hand, and literary criticism, on the other, is not the difference between rhetoric (or style) and something else, but between the different rhetorics that are powerful in the precincts of different disciplines; and the difference between the rhetoric of science-the rhetoric of proof, deduction, and mathematical certainty-and other rhetorics in modern society is a difference between a prestige discourse, a discourse that has for historical reasons become associated with the presentation of truth, and the discourses that will for a time measure themselves against it. I am not saying that these differences are illusory or that they don't have real consequences, only that their reality and their consequentiality are historical achievements-achievements fashioned on the anvil of argument and debate-and that as historical achievements they can be undone in much the same way they were achieved.

I have stressed the word "historical" in the previous paragraph because it names the sense Posner most egregiously lacks. He seems not to understand that the distinctions he so confidently invokes belong not to the nature of things but to conditions that have been put in place by exactly the labors-interpretive labors-that are supposedly constrained by those distinctions. He thus falls repeatedly into the error of regarding as universal the imperatives (both moral and methodological) that are perspicuous only within local (and therefore revisable) structures of conviction and belief. Consider, for example, the many-layered argument he makes regarding the constraints on interpretation inherent in the Eighth Amendment (forbidding "cruel and unusual punishment"). Because it has its origin in an historical context, Posner explains, a reader is not "free to imprint his

24. P. 1378.

25. P. 1376 . 
own reading" on the amendment; and if a court were to go so far as to find in the provision "a prohibition against sexually segregated prisons," its performance "would be as irresponsible as a literary critic's reading of Virgil's Fourth Eclogue, written before the birth of Christ, as a Christian allegory-which, as a matter of fact, is how it was read during the Middle Ages." ${ }^{26}$ Here Posner avails himself of what we might call the strategy of the double absurdity. He thinks it absurd that anyone would so interpret the amendment and he underlines his point by linking that interpretation with one even more obviously absurd, the impossibly anachronistic reading by a Christian exegete of a pagan poem. The point seems indisputable until one realizes that anachronism itself is a cultural concept, tied to a view of time as linear and irreversible and to a notion of agency as the property of discrete individuals. The possibility of regarding something as anachronistic emerges only within the assumptions we have inherited from the Enlightenment, assumptions that have conferred on science and its procedures the prestige they enjoy in Posner's essay; but within an older set of assumptions that are, in the end, inseparable from the hegemony of religion-the prestige discourse that science replaced-the reading of a poem in terms its (so-called) author could not possibly have known would be regarded not as anachronistic, but obvious and obligatory. That is to say, readers in the Middle Ages proceeded within the undoubted conviction of God's authorship of all human actions, physical and verbal, and given that conviction (which could not have been judged unreasonable, since it formed the field of relevance within which reasons emerged), a Christian reading of Virgil's poem, a reading that implied an author not bound by the constraints of chronology, would not be irresponsible, but compelled. Indeed, it would be incumbent upon anyone who wanted to take Virgil seriously - as opposed to dismissing him as an epiphenomenon of carnal history-to produce such a reading, and so bring him into line with the truths proclaimed by the Holy Scriptures. That is why, as Posner obligingly reports, the poem was read that way in the Middle Ages, not because (as his tone implies) medieval men and women didn't know any better, but because given what they knew with a certainty no less firm than that provided by the rhetoric of science, to read that way was nothing more (or less) than the exercise of common sense.

The point is a general one and will hold for Posner's "reading" of the way in which the Eighth Amendment could not be read responsibly. Here rather than looking backward to conditions of intelligibility that are no longer as generally in force as they once were, one need only look forward to conditions of intelligibility that have not yet fully emerged: All that is necessary for the practice of sexually segregating prisoners to be considered "cruel and unusual" would be a conviction strongly held in a society

26. P. 1370 (citation omitted). 
that sexuality and its exercise were at the very center of man's being; so that if people were asked, "What is the worst, most unbearable, organization of social life you can think of?," one often-given answer would be "sexually segregated." At that point (and it is a point some in our society have already reached), the classification of the practice as one enjoined by the Eighth Amendment would be obvious, would "go without saying," and to assert otherwise would be to be irresponsible.

Let me be clear. I am not saying that "anything goes," that interpreters of the Eighth Amendment (or Virgil's Eclogues) are presented with a "blank check" to be filled in as they like; only that insofar as the filling in of the check is constrained (and it always will be, Posner's positing of wholly free interpretive activity is as mistaken-it is the same mistake-as his positing of an interpretive act that is wholly prescribed), the constraints will inhere not in the language of the text (statute or poem) or in the context (unproblematically conceived by Posner as a "higher" and self-declaring text) in which it is embedded, but in the cultural assumptions within which both texts and contexts take shape for situated agents. And it will do no good to ask for a specification of those cultural assumptions (so that they could then serve as the constraint neither text nor context provides) because specifying is itself an act that occurs within assumptions that it cannot, at the moment of occurrence, specify. The moral is not that there are no such things as texts or acts, but that our ability to point to them or perform them depends on pre-articulations and demarcations they cannot contain; and it is only so long as such pre-articulations and demarcations are in place-and in a place we cannot locate because it locates and defines us-that texts and acts will have the immediate palpability they seem always to have.

The mistake is to confuse that palpability-the immediacy with which shapes make themselves available within local and historical conditions of intelligibility-with something inherent in those shapes, for that is the mistake of claiming for interpretively produced entities the status of being constraints on interpretation. It is a mistake Posner repeatedly makes when he distinguishes straightforward and specific language from vague and literary language, and argues (in, to be sure, a commonsense fashion) that the first is more constraining than the second. (This is the burden of numbers 2 through 11 on my list.) Here for example is his discussion of a supposedly unambiguous contract in relation to the operation of the parole evidence rule:

If a document states that it is the complete integration of the parties' contract, and the price stated in the document is $\$ 100$ per pound, the parole evidence rule will prevent the seller from later offering testimony that in the negotiations leading up to the contract the parties had agreed that the price would be $\$ 100$ per pound only for the first 
ten pounds after which it would be $\$ 120$ a pound. The document is not ambiguous. ${ }^{27}$

But Posner misses the point. The document is neither ambiguous nor unambiguous in and of itself. The document isn't anything in and of itself, but acquires a shape and a significance only within the assumed background circumstances of its possible use, and it is those circumstances-which cannot be in the document, but are the light in which "it" appears and becomes what "it," for a time at least, is-that determine whether or not it is ambiguous and determine too the kind of straightforwardness it is (again for a time) taken to possess.

It could well be that in the industry related to the contract of Posner's example it is understood by everyone experienced in the trade that when a price per pound has been negotiated, it goes without saying that there is an escalation of $20 \%$ after the first ten pounds. Within that understanding, the document would have, and have obviously and without dispute, the meaning Posner scoffs at. Of course within a different understanding, a different sense of the way business is typically done, the document will have just the obvious meaning Posner claims for it, but that obvious meaning will be no less circumstantial-no less the product of interpretive assumptions that are not in the text because it is within them that the text acquires intelligibility - than the meaning he rejects. ${ }^{28}$ This does not mean that the document is ambiguous, but that the shape of its straightforwardness (or of its ambiguity should that be the face it presents) will always be a function of something prior to it. Of course, one could always attempt to make that something (I have been calling it the background conditions of intelligibility) explicit and thereby (and this is Posner's word) "control" the document's interpretation; but the intelligibility of the language in which the background conditions were supposedly made explicit would itself be a function of still other background conditions that would not be "in" the text but would nevertheless be determinative of what everyone (or nearly everyone; there is always room for dispute) took to be its meaning. ${ }^{29}$ As a frequent flyer, I have been amused recently by the efforts of airlines to police their lavatories. In particular, I've noticed the now al-

27. P. 1371 .

28. The argument should surely be familiar to someone who has read cases in which the court begins by stating "The issue is, what is chicken?," see Frigaliment Importing Co. v. B.N.S. International Sales Corp., 190 F. Supp. 116, 116 (S.D.N.Y. 1960); or finds that "I guarantee to give you a perfect hand" is obviously not a guarantee, see Hawkins v. McGee, 84 N.H. 114, 146 A. 641 (1929); or declares that "a thing which is within the intention of the makers of a statute is as much within the statute as if it were within the letter," see Riggs v. Palmer, 115 N.Y. 506, 509, 22 N.E. 188, 189 (1889).

29. For discussion of the difficulty in trying to articulate these background conditions for "literal" language, see Fish, Normal Circumstances and Other Special Cases, Critical Inquiry, Summer 1978, at 625; see also J. SEARLe, Literal Meaning, in Expression and Meaning: StUdies in the ThroRY OF SPEECH ACTS 117 (1979). 
most desperate search for a sign whose wording will make absolutely and explicitly clear what should and should not be flushed down the toilet. The latest (and doomed) effort goes something like this: "Only toilet paper and tissue should be deposited in the toilet." How long will it be, I wonder, before stewards and maintenance men begin to find bodily waste, liquid and solid, deposited in the most inconvenient places, if only by wags who recognize and testify to the folly of thinking that language can be made so explicit as to preclude interpretation. Of course, one could add feces and urine to the list of proper things to deposit, but that would only fuel the game, not stop it. What stops the game when it is stopped (as it almost always is) is not the explicitness of words, but the tacit assumptions (concerning what toilets are for, and, on an even more basic level, what is and is not waste in a post-agricultural society) within which the words immediately take on an unproblematic (though interpretively produced) shape.

The point is a simple one: All shapes are interpretively produced, and since the conditions of interpretation are themselves unstable-the possibility of seeing something in a "new light," and therefore of seeing a new something, is ever and unpredictably present-the shapes that seem perspicuous to us now may not seem so or may seem differently so tomorrow. This applies not only to the shape of statutes, poems, and signs in airplane lavatories, but to the disciplines and forms of life within which statutes, poems, and signs become available to us. There is a temptation when considering these issues to concede the interpretive status of the objects and texts within an enterprise while claiming for the enterprise itself a reality less mutable and permutable, to argue, for example, that while legal and literary texts may change with changes in the conditions of interpretation, the disciplines themselves remain stable-continue always to be what they essentially are-as do the differences between them. Something like this seems to lie behind Posner's insistence that when all is said and done "the study of literature has little to contribute to the interpretation of statutes and constitutions."30 As I have already indicated, this seems to me a correct judgment; but while for Posner the judgment follows from the essential nature of the two disciplines, I see it as an accurate account of interpretive conditions presently - but not inevitably-in force. That is, while I agree with his assertion of difference, I disagree with his specification of its source and with his assumption of its durability.

The source for many of the differences Posner invokes is the supposedly master difference between legal and literary language; while the first is specific and historically tethered, the second is inherently ambiguous and

30. P. 1351. 
unconstrained: "[E]very great work of literature may well be unclear." This is simply the distinction between clear and unclear contracts writ large, as a distinction between disciplines rather than a distinction within a discipline, and it falls by the same argument: To the extent that literary texts are "unclear"-do not yield straightforward messages as do statutes or signs in lavatories-it is not because something called "literary language" has certain properties, but because literary critics (or at least some of them) approach their task already in possession of, or possessed by, a sense of what the object of their professional attention is like, and that sense, put into operation as a reading strategy, produces both the literary text and its (supposedly antecedent) properties. As I put the point some time ago:

If your definition of poetry tells you that the language of poetry is complex, you will scrutinize the language of something identified as a poem in such a way as to bring out the complexity you know to be "there." You will, for example, be on the look out for latent ambiguities . . . you will search for meanings that subvert or exist in a tension with the meanings that first present themselves. . . . Nor, as you do these things, will you have any sense of performing in a willful manner, for you will only be doing what you learned to do in the course of becoming a skilled reader of poetry. ${ }^{32}$

All of which is to say that as a fully situated member of an interpretive community, be it literary or legal, you "naturally" look at the objects of the community's concerns with eyes already informed by community imperatives, urgencies, and goals. Therefore, if it is the goal of your community to derive single lines of direction from particular texts (identified as the Constitution, statutes, precedents), your first glance at such a text will be informed by that interpretive disposition (indistinguishable from what you think, in advance, the text is for and also from what you take to be your relation to it), and you will see, and by seeing produce, that kind of text. Conversely, if it is the goal of your community to derive as many lines of direction as possible from a text, your first glance at it will be informed by that interpretive disposition (and, remember, reading independently of an interpretive disposition, of some already in-place sense of the enterprise in relation to which this is a text, is impossible) and multiple meanings will force themselves upon your attention. Obviously, with respect to the two communities and their enterprises, interpretive activity will be different, but rather than being a difference that follows from the essential nature of law and literature or from the essential properties of legal and literary language, the difference will be originary, assumed in

31. P. 1371 .

32. S. Fish, Is There a Text in This Class? 327 (1980). 
advance and then put into operation so as to produce the formal "evidence" of its rightness, the evidence of straightforward or ambiguous language, or of legal as opposed to literary significances.

One cannot then ground the difference between literary and legal interpretation in the different kinds of texts they address, because the textual differences are themselves constituted by already differing interpretive strategies, and not the other way around. Nor can one turn this insight into a new reification of difference by assuming that the strategies specific to law and literature are themselves basic and unchanging, for they are no less historically achieved (and therefore contingent) than the texts they enable us to produce. While it is true that an agent embedded in an enterprise proceeds with a firm, if tacit, sense of what the enterprise is (of what and who it is for and by what routines it accomplishes its ends) and therefore with a sense of the differences between it and the other enterprises that it is not, that sense is itself revisable, and if it is revised (it needn't be-there is nothing inevitable about any of this), the difference between the enterprise (conceived of as a set of interpretive dispositions) and some others may become less sharp. As things stand now in our culture, a person embedded in the legal world reads in a way designed to resolve interpretive crises (although as Walter Michaels reminds me, after he was reminded of it by a practicing lawyer, at some stages in the preparation and even the arguing of cases, the proliferating of interpretive crises is just the skill called for), while someone embedded in the literary world reads in a way designed to multiply interpretive crises. ${ }^{33}$ It could, however, be otherwise, and is otherwise even today in some Latin American cultures where literary productions are understood to issue from specific political agendas in whose direction they unambiguously point. (We all, of course, remember the Cultural Revolution in China, with its stipulation as to the content and message of works that purported to be literature.) To the objection that in such cultures the essence of the literary has been violated one must reply that what the examples show (and countless others could be educed; the story Posner tells in which the literary is equated with the effusions of genius as it rises above the constraints of any local sociopolitical context has been told only since the beginning of the nineteenth century, and one might reasonably argue that in the long sweep of history it is an anomaly) is that literature has no essence, only the succession of forms it takes in different social settings where the space of the literary-its differential relationship to the activities that limit and enable its possible actions-is differently opened up..$^{34}$

At times Posner seems to see this, at least on the legal side of the ques-

33. I have made this point before in response to Owen Fiss. See Fish v. Fiss, 36 STan. L. Rev. $1325,1344-45$ (1984).

34. For general discussion of changes in Western cultural understanding of the "literary," see T. EAgleton, Literary TheORY 1-53 (1983). 
tion, as when, after declaring, "If I want to learn about fee entails I do not go to Felix Holt," he adds, "Obviously this is not true in cultures where the only information about law is found in what we call literature, though contemporaries thought of it as history . . ." Ags Again I want to agree with Posner that in our culture a legal agent does not go to novelists for legal instruction when more authorized sources of instruction are readily available; but I would insist that these other cultures (which would of course include the medieval culture whose infrastructure he dismisses or ignores) are fully as realized as ours and that the institutional arrangements they display-arrangements that in some cultures result in law being indistinguishable from religion or prophecy-do not necessarily (although it may turn out to be so empirically) represent primitive stages of realization that the race has long since gone beyond. I am not here retailing some cheap relativism which would disable us from preferring our arrangements to theirs; rather, I am saying that whatever preferences we have are themselves historically constituted in relation to various contending political and social agendas, and that when we defend them or reiterate them (as Posner does here) we are doing so not in the name of some transparent truth, but in the name of interests whose universality is always contestable.

What are Posner's interests? The question may seem abrupt and unrelated to the linguistic and philosophical arguments of the preceding pages, but in fact it is a question Posner himself invites in those places where he invokes the notion of "power" as still another way of distinguishing between legal and literary interpretation. The argument is that since literary critics operate in a realm where consequences are minimal-what harm, after all, will be done if a critic substitutes "his will for that of Wordsworth or Yeats"36 -it does not matter that much if their actions are (relatively) unconstrained. Lawyers and judges, on the other hand, operate in the public world of government and regulation and "[i]n our society the exercise of power by appointed officials . . . is tolerated only in the belief that the power is somehow constrained." While "[t]he critic who interprets an ambiguous work of literature is not imposing his view on anyone else . . . the court that interprets an ambiguous provision . . . is imposing its view on the rest of society, often with far-reaching practical consequences." ${ }^{38}$ One could question this distinction from several directions, by arguing, for example, that the actions of literary critics can have consequences as far reaching and practical as the decision of any court. The judgment of an authoritatively placed literary critic (Matthew Arnold, Lionel Trilling, T.S. Eliot) can have a profound and direct effect on what

\footnotetext{
35. Pp. 1356-57.

36. P. 1373.

37. P. 1370 .

38. P. 1373.
} 
gets taught in the schools, what appears in the curriculum, what gains entrance into the canon, what gets published, reviewed, anthologized, disseminated, and in all of these ways can finally have an effect on the very structure of a culture, its favored myths, storehouse of moral values, modes of intellectual inquiry, etc. I am not saying that these effects are the same as the effects of a judicial pronouncement (although the edicts of some literary critics have precisely that force), but that they are no less "far reaching," and that the difference between them is the difference between differing spheres of and routes to consequentiality, not the difference between consequentiality and its opposite.

This is of course a version of the argument I have been making all along in which I challenge Posner's laying down of essentialist distinctions by the double strategy of first denying the distinctions and then historicizing them. But for the moment I am less interested in challenging the distinction between legal and literary consequentiality than in asking for what reason-in the service of what agenda-Posner makes it, and the answer to this question puts a new twist on his discussion of power. For it turns out that Posner's attribution of powerlessness to literary interpretation, at least in comparison to legal interpretation, is itself a (disguised) move in a power game. The stakes in the game are named in the very first sentence of the essay: "After a century as an autonomous discipline, academic law in America is busily ransacking the social sciences and the humanities for insights and approaches with which to enrich our understanding of the legal system." 38 The issue then is the autonomy of academic law, and it of course has been the issue in every one of the distinctions so far discussed. The implication is that Posner will reassert that autonomy in the face of recent challenges to it. But that is a less than candid view of the matter since he says nothing at all about the social sciences (and it is hard to see how he could, given his determination to hand over academic law to one of them on a silver platter); rather, he turns his critical attention to literary studies and argues, as we have seen, for their irrelevance to the legal system, an irrelevance attributed at least in part to the extent to which they are removed from the operations of real power, are not where the action is. But what is presented as a dismissal rendered from a position of strength-the sitting Judge hears the case of the petitioning literary critics and finds it weak-is in fact an action far more defensive, for what Posner fails to report are the incursions already made into academic law, and particularly into the domain of legal interpretation, by literary studies. His admonition-don't look for very much help from literary studies-comes too late; for, as he surely knows, recent years have seen an unprecedented traffic between legal and literary studies, with the former borrowing and appropriating far more than the latter,

39. P. 1351. 
and to considerable effect. Not only is it now difficult to tell some numbers of the Stanford Law Review or The Yale Law Journal from Diacritics and Critical Inquiry, but the issues debated in their pages have spilled out into tenure battles, the restructuring of curricula and even of whole law schools, and produced a general sense in the legal profession of a new crisis in which its authority-internal and external-is being put into question as never before. This, of course, is what the Critical Legal Studies Movement is all about, and it is from literary analysis of interpretation that this movement takes many of its arguments and techniques. The fact that Posner does not even refer to the movement is of a piece with the strategy I have already noted: Committed to a weak position-weak because the developments he warns against have already occurred-he hides its weakness by neglecting to mention those developments.

Of course, he does more than that: He puts forward an argument against the significance of the developments he neglects to mention. It is, he declares, a "great false hope" that literary theory "will change the way in which lawyers think about the interpretation of statutes and the Constitution." ${ }^{40}$ That, it seems to me, is an empirical question, and the evidence is not yet in. I agree with Posner that given the present construction of the legal world, a deconstructive interpretive theory will not be readily translatable into a viable legal practice (this is, of course, the problematic that continually engages the Critical Legal Studies Movement); but it could be the case that the dissemination of such a theory might play a role in altering the way in which the legal world is constructed by altering the ways in which legal actors conceive of their activities. Indeed there is already evidence that literary theory has changed the way in which some lawyers think about the interpretation of statutes and the Constitution, and it is at least possible (but not inevitable) that this change in the characterization of interpretive labors (of what they are "really" like) could play a role in changing those labors themselves. The evidence I am thinking of includes citations by courts of pieces in the pioneering Texas Law Review special issue on interpretation ${ }^{41}$ and the introduction into the Bork hearings of arguments about intention and literal meaning that are obviously derived from the writing of prominent literary critics. To be sure the evidence is inconclusive and the vast majority of legal business is still done within the traditional notions of literal meanings, transparent intentions, determinate texts, and stable precedents; but if certain forces in the legal academy grow more numerous and outlive their detractors (the second is a certain occurrence), then who knows?

I referred earlier to some significant omissions in Posner's argument: His silence on the subject of economics after mentioning the social sciences

40. P. 1360.

41. Law as Literature, 60 Tex. L. Rev. 1 (1982). 
in the first sentence; his failure to acknowledge the Critical Legal Studies Movement even by name, although one member of that movement (Gary Peller) is scorned in a footnote. ${ }^{42} \mathrm{I}$ call these omissions significant because they alert us, as omissions often do, to the real and not-so-hidden agenda that lurks behind the one forthrightly proclaimed. Although Posner says nothing about economics, the effort he mounts here to de-authorize literary studies is intended to clear the field so that the authority of economics in the legal academy can be secured; and since members of the Critical Legal Studies Movement are among the most prominent and forceful opponents of Law and Economics, Posner is obliged to disarm them, which is precisely what he will succeed in doing if he manages to discredit the discipline from which they take so much of their arsenal. The entire essay, then, is something of a feint; it directs our attention to the supposed limitations of literary interpretation but its primary, if unstated, purpose is to legitimize the interpretive strategies authorized by economics.

By and large, the feint is successful, but there are several ostensibly literary moments where the economic agenda peeps through. One occurs in the context of Posner's repeated assertion that literary works are not to be read with the intentions of the author in mind since when they are deciphered or reported the intentions of authors-statements as to what they meant-are often banal. His example is the poetry of Ezra Pound, which, he says, is often "quite beautiful"; but its beauty, he continues, has nothing to do with the messages Pound apparently intends, which are at times "false and even absurd" as in those passages "that denounce usury." " 3 Pound has of course been faulted for many things, but one wonders what kind of reader would single out the critique of usury as a particularly objectionable feature of his poetry. The answer, of course, is a proponent of the doctrines of Law and Economics, and it would seem that at some level Posner detects in the perspectives offered by literary and deconstructive theory a danger to the program with which he is so closely associated. It is after all a thesis of deconstructive theory that forms of representation, of which any system of currency is an instance, are always agencies of power and manipulation and never simply stand in for natural forces like the market. Perhaps the trouble with literary studies is not that they are irrelevant but that, at least potentially, they are too relevant.

A second moment at which Posner's possibly wider agenda can be spied occurs in a footnote. The note is to a discussion of Shakespeare's Merchant of Venice in which Posner argues that although "[a]t one level the play is about the enforcement of a contract that contains a penalty clause," $" 4$ that is not its real point. The real point is, of course, metaphori-

42. P. 1363 n. 45.

43. P. 1379 .

44. P. 1357. 
cal and general and therefore nothing one need worry about. The footnote to the argument cites a 1964 book entitled Shakespeare's Politics by one A. Bloom, whom we have recently come to know as Allan Bloom, the author of The Closing of the American Mind, ${ }^{45}$ a sustained diatribe against exactly the theory and theorizing that Posner is declaring to be beside the legal point. One could pursue many paths here beginning perhaps with a counter-reading of The Merchant of Venice in which the center of the play is precisely the contract, and its lesson is the rejection of both literalism and usury as complementary realizations of a spiritual poverty, a lesson Posner would surely find uncomfortable. Or one could explore the "Chicago connection," which finds a neo-conservative disciple of Leo Strauss cited by a neo-conservative legal economist who in the company of (among others) a prominent former Dean of the University of Chicago Law School supported the nomination to the Supreme Court of a neo-conservative literalist and formalist who publicly attributed his theoretical awakening to a period spent in that same university. Or one could go in still another direction and note the repeated appearance in Posner's notes of E.D. Hirsch, another intellectual with connections to Chicago who, along with the aforementioned Bloom, is providing Secretary of Education William Bennett and others with ammunition for their attack on the humanities in general and on literary interpretivism in particular; an attack that has been recently stepped up in the press, and will soon, I am told, be receiving congressional attention. But whichever path one followed (and there are others) the result would be to highlight the extent to which Posner's essay, as innocently occasional as it might seem, is part and parcel of a wholesale effort to restructure several key American institutions in accordance with a very definite, and some would say extreme, political and moral vision.

It might seem that I am inflating the significance of what is after all a slight and flawed piece, full of misinformation and blunders (including the howler of criticizing Shakespeare for his "failure" to publish his plays, ${ }^{{ }^{6}}$ ) uncomprehending of the positions to which it is opposed, finally less an argument than a collection of outdated pieties. Indeed, it might seem suffi-

45. A. Bzoom, The Closing of the American Mind (1987).

46. P. 1367. Again the point hinges on an awareness of historical context. It would have required a cognitive restructuring for Shakespeare and his contemporaries to have seen his plays as "literature," that is, as permanent and stable verbal objects. Rather, they would have regarded a play as something recreated in its every performance. The notion of the Shakespearian text as something sacred, fixed, and publishable, is a product of Shakespeare studies. One might say that the decisive gesture is Ben Johnson's: He publishes his own plays in 1616 and therefore makes thinkable the subsequent publication in $\mathbf{1 6 2 3}$ of the Shakespeare folio. Posner's mistake is to assume that notions like authorship, property, literature, and text, are stable across time and are basic components of any literary culture. For an admirably concise summary, see Orgel, The Authentic Shakespeare, 21 REPResentations 1 (1988); see also Orgel, Prospero's Wife, 8 Representations 1 (1984); Foucault, What Is an Author?, in Textual STRATEgies 141 (J. Harari ed. 1979) (discussing historical contingency of concepts of author and literary "work"). 
cient to leave the judgment of it to the full verse from which my title is taken:

Don't know much about the Middle Ages,

Look at the pictures and turn the pages;

Don't know much about no rise and fall;

Don't know much about nothing at all. ${ }^{47}$

But while there would be a certain satisfaction in this gesture, it would be too easy and it would reproduce the mistake for which I have criticized Posner, the mistake of accepting at face value the boundaries that separate disciplines and render their respective activities discrete from one another. In fact, neither disciplines nor the activities they enable are discrete, but exist in networks of affiliation and reciprocity that can sometimes be glimpsed (as they are here) in footnotes that reveal how a position taken in one corner of the institutional world is authorized by and authorizes in its turn positions of a similar kind taken elsewhere. Given the structural interdependence between disciplines, the effects of a piece of writing will always extend to contexts apparently far removed from the ones explicitly addressed; and this will be especially true in the case of someone like Posner, who is after all an appellate judge of national reputation and a scholar of enormous influence. This means that when he pronounces on something-even when, as in this case, the pronouncement is uninformed and slipshod-he will receive a respectful hearing, and therefore it is incumbent upon those who find his views not only wrong, but supportive of wrong views now being put forward in other (sometimes high) places, to challenge them in the strongest terms possible.

47. What a Wonderful World (L. Adler, W. Alpert \& S. Cooke) (song lyrics). 
